\title{
WEIGHTED OPERATOR-VALUED FUNCTION SPACES APPLIED TO THE STABILITY OF DELAY SYSTEMS
}

\author{
Asmahan E. Alajyan and Jonathan R. Partington*
}

\begin{abstract}
This paper extends the theory of Zen spaces (weighted Hardy/Bergman spaces on the right-hand half-plane) to the Hilbert-space valued case, and describes the multipliers on them; it is shown that the methods of $H^{\infty}$ control can therefore be extended to a family of weighted $L^{2}$ input and output spaces. Next, the particular case of retarded delay systems with operator-valued transfer functions is analysed, and the dependence of $H^{\infty}$ structure on the delay is determined by developing an extension of the Walton-Marshall technique used in the scalar case. The method is illustrated with examples.
\end{abstract}

Mathematics subject classification (2020): 30H10, 30H20, 44A10, 46E15, 47N70, 93B36.

Keywords and phrases: Hardy space, Bergman space, Zen space, Plancherel theorem, $H^{\infty}$ control, retarded delay system, stability, subnormal operator.

\section{REFERENCES}

[1] W. Arendt, C. J. K. Batty, M. Hieber And F. Neubrander, Vector-valued Laplace transforms and Cauchy problems, Second edition, Monographs in Mathematics, 96, Birkhäuser/Springer Basel AG, Basel, 2011.

[2] R. Bellman And K. L. Cooke, Differential-difference equations, Academic Press, New YorkLondon, 1963.

[3] C. Bonnet And J. R. Partington, Analysis of fractional delay systems of retarded and neutral type, Automatica J. IFAC 38 (2002), no. 8, 1133-1138.

[4] J. BRAM, Subnormal operators, Duke Math. J. 22 (1955), 75-94.

[5] J. B. Conway, Subnormal operators, Research Notes in Mathematics, 51. Pitman (Advanced Publishing Program), Boston, Mass. London, 1981.

[6] B. A. FRANCIS, A course in $H_{\infty}$ control theory, Lecture Notes in Control and Information Sciences, Springer-Verlag, Berlin, 1987.

[7] Z. HARPER, Boundedness of convolution operators and input-output maps between weighted spaces, Complex Anal. Oper. Theory 3 (2009), no. 1, 113-146.

[8] Z. HARPER, Laplace transform representations and Paley-Wiener theorems for functions on vertical strips, Doc. Math. 15 (2010), 235-254.

[9] R. A. Horn AND C. R. Johnson, Matrix analysis, Corrected reprint of the 1985 original, Cambridge University Press, Cambridge, 1990.

[10] B. Jacob, A. Mironchenko, J. R. Partington and F. Wirth, Noncoercive Lyapunov functions for input-to-state stability of infinite-dimensional systems, SIAM J. Control. Optim. 58 (2020), no. 5, 2952-2978.

[11] B. Jacob, J. R. Partington And S. Pott, On Laplace-Carleson embedding theorems, J. Funct. Anal. 264 (2013), no. 3, 783-814.

[12] B. JACOB, J. R. PARTington And S. PotT, Applications of Laplace-Carleson embeddings to admissibility and controllability, SIAM J. Control Optim. 52 (2014), no. 2, 1299-1313.

[13] J. R. Partington, Linear operators and linear systems. An analytical approach to control theory, London Mathematical Society Student Texts, 60, Cambridge University Press, Cambridge, 2004

[14] V. I. Paulsen and M. Raghupathi, An introduction to the theory of reproducing kernel Hilbert spaces, Cambridge Studies in Advanced Mathematics, 152. 
[15] C. R. Putnam, The spectra of subnormal operators, Proc. Amer. Math. Soc. 28 (1971), 473-477.

[16] M. Vidyasagar, Control System Synthesis: A Factorization Approach, MIT Press Series in Signal Processing, Optimization and Control, 7, 1985.

[17] K. Walton AND J. E. MarshaLl, Direct method for TDS stability analysis, IEE proceedings D, control theory and applications 134 (1987), 101-107.

[18] K. Zhou, J. C. Doyle And K. Glover, Robust and Optimal Control, Prentice-Hall, Inc., Upper Saddle River, 1996. 